\title{
ENTRE O FIM DO MUNDO E O AMANHÃ: IMAGINAÇÃO POLÍTICA ANTAGONISTA NO MERCADO EDITORIAL BRASILEIRO APÓS 2018
}

\author{
Between the "end of the world" and "tomorrow": antagonist political \\ imagination in the Brazilian publisher market after 2018
}

\section{Entre el "fin del mundo" y el "mañana": la imaginación política antagonista en el mercado editorial brasileño tras 2018}

Carolina Cavalcanti Falcão

Pesqusiadora Pós-Doc, Programa de Pós-Graduação em Direitos Humanos - UFPE

carolinacfalcao@gmail.com

\section{Resumo}

Neste trabalho desenvolvo e apresento a ideia de imaginação política antagonista, um fenômeno político editorial, marcado por um esforço duplo: a elaboração crítica da atual conjuntura brasileira após as eleições presidenciais de 2018 e a concepção de formas de resistência nesse contexto. Para isso, levo em consideração, entre os títulos publicados no Brasil em 2019, as obras de Ailton Krenak e Rosana Pinheiro Machado, "Ideias para adiar o fim do mundo" e "Amanhã vai ser maior", respectivamente. Argumento que as concepções de "fïm do mundo" e "amanhã maior" trazidas nos títulos revelam como essa imaginação é produto também de um trabalho articulador do antagonismo político, a partir das proposições de Ernesto Laclau e Chantal Mouffe.

Palavras-chave: Imaginação Política. Antagonismo. Mercado Editorial.

\begin{abstract}
In this paper, I develop and present the idea of antagonistic political imagination, a publisher and political phenomenon, marked by a double effort: the critical elaboration of the current Brazilian situation after the 2018 presidential elections and the conception of forms of resistance in this context. For that, I take into consideration, among the titles published in Brazil in 2019, the works of Ailton Krenak and Rosana Pinheiro Machado, "Ideas to postpone the end of the world" and "Tomorrow will be bigger", respectively. I argue that the conceptions of "end of the world" and "greater tomorrow" in the titles reveal how this imagination is also the product of an articulating work of political antagonism, based on the propositions of Ernesto Laclau and Chantal Mouffe.
\end{abstract}

Key words: Political Imagination. Antagonism. Publisher Market.

\section{Resumen}

En este artículo desarrollo y presento la idea de imaginación política antagónica, un fenómeno político editorial, marcado por un doble esfuerzo: la elaboración crítica de la situación brasileña actual después de las elecciones presidenciales de 2018 y la concepción de formas 
de resistencia en este país. contexto. Para ello, tomo en consideración, entre los títulos publicados en Brasil en 2019, las obras de Ailton Krenak y Rosana Pinheiro Machado, "Ideas para posponer el fin del mundo" y "Mañana será más grande", respectivamente. Sostengo que las concepciones de "el fin del mundo" y "un mañana más grande" en los títulos revelan cómo esta imaginación es también el producto de un trabajo articulador de antagonismo político, basado en las proposiciones de Ernesto Laclau y Chantal Mouffe.

Palabras clave: Imaginación Política. Anatgonismo. Mercado Editorial.

\section{INTRODUÇÃO}

"Se o impensável acontecer, mantenha a calma". Foi com esse título que Heloísa Starling publicou um ensaio sobre a reação de livrarias independentes nos Estados Unidos ao processo eleitoral de 2016, que escolheu Donald Trump o $45^{\circ}$ presidente americano (STARLING, 2020). No texto, a autora explica que esses estabelecimentos criaram no dia da posse do presidente (20/01/2017) a campanha "Leia e aja" na qual distribuíam gratuitamente livros que tratavam sobre questões ligadas ao autoritarismo. A "energia política" articulada em oposição aos valores que a emergência de Trump como presidente já havia chamado a atenção da autora que, num texto anterior (de 2017), explicava:

Grupos de ativistas entraram no circuito, se cotizaram e compraram edições inteiras desses livros para serem distribuídas ao público. O sujeito entrava na livraria, ganhava de presente um exemplar e recebia uma recomendação: "Leia e aja". A estratégia era cristalina: os livros deveriam atuar como uma espécie de antivírus para prevenir, detectar e proteger a sociedade americana contra a entrada do autoritarismo e da intolerância. (STARLING, 2017)

Os livros em questão eram majoritariamente ficcionais e revelavam distopias típicas do século XX: “1984”, de Geroge Orwell; “Admirável Mundo Novo”, de Aldous Huxley e “O Conto de Aia", de Margareth Atwood. Segundo Starling, eram títulos "que refletiam sobre a essência terrível da dominação em regimes extremos recorrendo ao pesadelo futurista da distopia" (STARLING, 2020). No entanto, um livro situado na "fronteira entre a história e a teoria política" mereceu destaque na análise do caso. "As origens do Totalitarismo", de Hannah Arendt, de 1951, também estava na lista dos livreiros e sua recepção foi tão significativa que emplacou uma inesperada $25^{\mathrm{a}}$ posição na lista dos mais vendidos do USA Today. Para a autora, uma escolha certeira tendo em vista a estratégia de provocar os leitores a pensarem sobre as formas totalitárias de poder e motiva-los a uma (re)ação.

No Brasil após as eleições presidenciais de 2018, uma situação semelhante também uniu resistência e afronta ao poder estabelecido à estratégia de distribuição gratuita de livros. Foi durante a realização da Bienal do RJ, em setembro de 2019, quando o então prefeito da 
cidade Marcelo Crivela enquadrou como conteúdo pornográfico e impróprio para menores uma edição da História em Quadrinhos (HQ) Vingadores, que mostrava uma cena de dois personagens homens se beijando. A decisão, amparada pelo então presidente do Tribunal de Justiça do Rio, fez com que o Youtuber e influencer Felipe Neto comprasse da própria Bienal 14 mil exemplares com temática sobre diversidade sexual para serem distribuídos gratuitamente. Em entrevista ao Estadão, Felipe falou de sua expectativa sobre a atitude:

Não imagino que as pessoas vão ficar contra livros serem distribuídos gratuitamente para a sociedade. Num país onde a gente precisa aumentar e incentivar a leitura e o consumo de livros, acho que é uma ação onde só tem coisas positivas acontecendo. (Estado de São Paulo, 2019).

Num vídeo postado em seu canal no Youtube sobre a ação, Felipe Neto explicou como seria feita a distribuição dos livros e finaliza sua postagem com um recado para o prefeito carioca:

Esse é um recado pro Crivella. Crivella, eu estou falando com você agora. Eu fiz isso pra te mostrar... que não tem como você ganhar isso. É impossível! Não tem como vocês reprimirem a população... em pleno 2019! Esse foi só um exemplo... das milhões de coisas que nós, como população, podemos fazer... Pra lutar contra o autoritarismo! Pra lutar contra essa vontade ditatorial de... colocar as regras que vocês têm pra si... pra todos os outros. Nós não vamos viver sob essas regras! Vocês não vão vencer essa batalha, ok? ${ }^{1}$

Segundo Ferreira (2019), um dia após o decreto do TJ-RJ, as companhias montaram prateleiras específicas com a temática LGBT e viram a procura pelos títulos aumentar significativamente. O título-alvo da ação, Vingadores - a cruzada das crianças, uma HQ lançada em 2012 que chegou ao Brasil em 2016, esgotou-se poucas horas depois do ocorrido. $\mathrm{Na}$ Internet, exemplares eram negociados por até $\mathrm{R} \$ 250$, anunciados como "a HQ censurada".

\section{O MERCADO EDITORIAL E O ANTAGONISMO POLÍTICO}

Quero pensar esses dois acontecimentos como ponto de partida para assumir uma forma de leitura como prática antagônica a uma dada ordem política. Para isso, pretendo, a partir do aspecto estratégico que envolve os casos (a disponibilização gratuita é um ponto interessante, mas não central nessa questão), tocar na premissa mesma que mobiliza tal ação, qual seja a ideia de que é preciso ler para entender e agir/resistir. Considerando essa premissa, é possível falar de um movimento editorial pautado pela "energia política" do antagonismo.

1 Vídeo disponível em: https://www.youtube.com/watch?v=meqsHqP4Qw4\&t=2s, acesso em 30 de abril de 2020 . 
Para isso, é importante levar em consideração o protagonismo como o "limite do social", como proposto por Laclau e Mouffe (2015). Eles explicam que a ideia de limite do social é tida como algo que se observa no interior do próprio social. Segundo os autores, os antagonismos "constituem os limites da sociedade, a impossibilidade desta última se constituir plenamente" (p. 203). Em outro trecho, elaboram: "A sociedade nunca consegue ser plenamente sociedade, porque tudo nela é atravessado pelos seus limites, os quais a impedem de constituir-se como uma realidade objetiva” (p. 204). Cabe, portanto, aos trabalhos de análise baseados nessa ideia entender como essa subversão se constitui discursivamente, o que, para os autores, requer determinar as formas de presença do antagonismo. No contexto em que a ideia de antagonismo foi primeiramente elaborada pelos autores, o conceito fornece uma premissa fundamental no trabalho da dupla sobre a hegemonia: as relações políticas não se travam entre identidades prontas. Ou seja: é preciso abandonar o caráter essencialista das identidades políticas e assim avançar na própria ideia de hegemonia. Tomando a reflexão dos autores, o antagonismo é a presença discursiva da "experiência de limite" que as identidades políticas experimentam.

Como, então, essa presença antagônica pode ser percebida no atual mercado editorial brasileiro? O que ela produz em termos da articulação ler/entender/agir, premissa das ações ativistas que ilustraram a abertura desse trabalho? Entendo que existe uma relação direta entre a formulação dessas perguntas e a observação, já a partir de 2018, de um campo progressista diverso partilhando um posicionamento em comum: a oposição ao contundente fortalecimento do pensamento da extrema direita no país, que vai culminar na eleição de Jair Bolsonaro à presidência da República. Minha hipótese é que uma das formas de reprodução simbólica desse antagonismo se encontra precisamente na dinâmica de produção editorial, ensejando uma modalidade de presença que encontra no livro uma forma de distinção e inscrição no espaço público de forma mais prestigiosa.

Há um arquivo de produções editoriais pautadas por essas posições antagônicas, elaboradas por figuras públicas que se opuseram ao projeto político vitorioso nas eleições de 2018, e tomadas por uma energia política que chama atenção. Utilizarei nesse trabalho, dois títulos que fazem parte desse repertório de livros publicados em 2019, primeiro ano da gestão de Bolsonaro à frente da presidência. São eles: “Amanhã vai ser maior”, de Rosângela Pinheiro Machado e "Ideias para adiar o fim do mundo", de Ailton Krenak. O referido ano foi marcado também pelo lançamento de outros títulos que se inscrevem nessa imaginação antagonista, "Por que lutamos", de Manuela D'Ávila; "Pequeno Manual Antirracista", de 
Djamila Ribeiro; “O que será?”, de Jean Wyllys e "Amor como revolução", de Henrique Vieira. A escolha dos dois títulos levou em consideração o fato de os autores falarem de lugares sociais completamente diferentes (ele, um líder indígena e ela, uma antropóloga e professora universitária) produzindo uma dispersão enunciativa interessante para a formulação da posição antagonista.

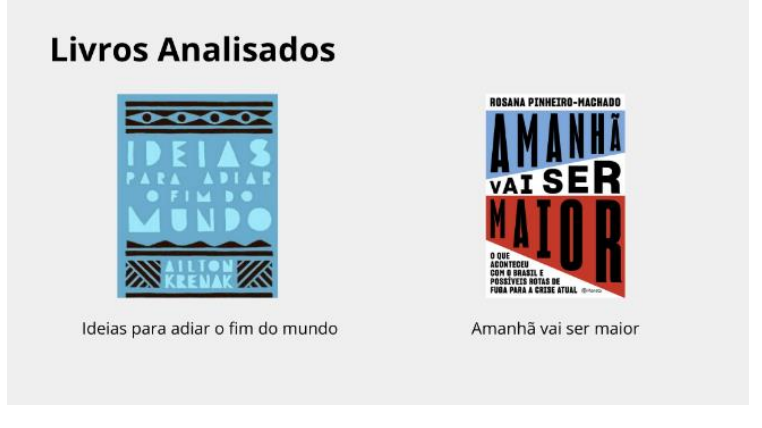

Imagem 1- Livros analisados no trabalho

Acredito que existe um dado relevante no fato de que os seis títulos tenham sido lançados no mesmo período. Isso revela não só um esforço interpretativo, em última instância, da realidade nacional, mas também um significativo contraponto à forte investida, no mercado editorial, do pensamento conservador da nova direita. Como explica Silva (2018), a década de 2010 é marcada pelo vigor comercial do "politicamente incorreto" nesse setor. Para ele, uma cultura revisionista e opositora às minorias, que abarrotou as megastores com títulos do tipo. É preciso também levar em consideração a conjuntura da época, marcada pelo enfraquecimento da agenda política da esquerda, cujo emblema mais significativo era o Partido dos Trabalhadores. Ele explica: “O politicamente incorreto abriu uma janela de oportunidade para a nova direita tornar-se protagonista na cena política e passar a colocar-se efetivamente como oposição ao governo do PT e às minorias" (p. 61).

Comentando, ainda em 2015, sobre o fenômeno comercial dessa direita produtora de best-sellers, Rodolfo Borges cita em matéria para o El País uma relação de livros que passaram a ocupar as listas dos mais vendidos no país. Autores como o filósofo Olavo de Carvalho, o blogueiro Felipe Moura Brasil, o jornalista Reinaldo Azevedo e o economista Rodrigo Constantino. Esse aumento de publicações foi tratado no texto como uma "saída do armário" e revela um fenômeno que marca o "fim da ressaca do período da ditadura militar (1964-1985), associada à direita. Há até pouco tempo, nem parlamentares do antigo PFL se diziam de direita, e ninguém no mainstream se arvorava a defender discursos que não envolvessem a palavra desigualdade" (BORGES, 2015). 


\section{PARA ALÉM DA POLARIZAÇÃO, A IMAGINAÇÃO ANTAGONISTA DA DREAMPOLITIK}

O mercado editorial não passa impune a essa disputa de narrativas entre uma direita que "saiu do armário" e se tornou hegemônica e uma esquerda que se articula a partir do lugar de antagonismo. Como explicam Heinen, Ribeiro e Ortellado (2019) em pesquisa sobre o mercado editorial de não-ficção, existem no país praticamente dois mercados em ação: um à direita, e outro à esquerda. Enquanto os títulos da direita apresentam uma certa homogeneidade (formando um grande conglomerado que vai do liberalismo econômico ao conservadorismo moral), no espectro da esquerda predomina um cenário nuançado, que abarca "títulos com uma perspectiva progressista, entrelaçados com outro grupo contendo obras de Karl Marx e de teoria marxista. Sobreposto a eles, há um terceiro subgrupo com feminismo, questões raciais e temas LGBT" (HEINEN; RIBEIRO; ORTELLADO, 2019). Em comum, ressalvam os autores, abundam nos dois grupos persistentes críticas ao adversário.

Muito embora a pesquisa acima possa nos fornecer pistas de um binarismo contundente, quero manter um posicionamento crítico em relação à ideia de polarização para interpretar esse contexto. Significante problemático, o termo vem sendo usado como um diagnóstico do contemporâneo político no país sobretudo após as manifestações de junho de 2013, numa importação do debate americano. Como aponta Nunes (2020), houve durante as manifestações, um fortalecimento da ideia de uma "pós-política" ou "consenso centrista" e a polarização, nesse sentido, passou a funcionar tanto como sintoma quanto instrumento desse processo. Ele explica:

"Sintoma", pois quanto mais uma pessoa se identifique com um extremo do espectro, mais ela tenderá a construir essa identidade de modo totalizante, relacionando-se com iguais, informando-se a partir de certas fontes, percebendo o espaço político como bipartido, e o lado oposto, de maneira monolítica. Isso fará com que tudo que fuja à sua própria norma pareça "radical", e que a simples participação do outro (mulheres, negros, pessoas trans etc.) no debate público possa ser experimentada como ofensiva. "Instrumento", porque acusar os adversários de assumirem posturas radicais oferece a quem acusa um pretexto para a própria radicalização (NUNES, 2020).

Proponho, assim, uma análise que ultrapasse o duplo sintoma-instrumento de um modelo polarizado/polarizador e descortine uma reflexão atenta às formulações desse campo progressista no mercado editorial nacional. Para isso, minha proposta leva em consideração o diagnóstico desenvolvido por Dardot e Laval (2016) que aponta a existência de uma "pane de imaginação" que acomete sistematicamente a esquerda numa perspectiva global. Para reverter 
esse quadro, os autores preveem o desenvolvimento de uma "capacidade coletiva que ponha a imaginação política para trabalhar a partir das experimentações e lutas do presente" (p. 9). Minha proposta é que existe uma imaginação antagonista em funcionamento nessas obras e ela funciona tanto como chave de compreensão analítica do presente nacional como elaboração da ação e resistência.

Entendo que as produções editorias inscritas na imaginação política antagônica compõem o que Duncombe (2017) estabelece como a Dreampolitik. Para o autor, existe uma grande defasagem imaginativa dos setores mais progressistas da sociedade, o que explicaria ao menos em parte a eleição de Donald Trump como presidente dos Estados Unidos e fenômenos similares pelo mundo. Ele aponta que as diretrizes adotadas pela esquerda estão fortemente marcadas por uma linguagem racionalista fria e exclusivista, que pouco se comunica com o desejo das pessoas. O espetacular, por outro lado, parece ser cada vez mais a estratégia dos setores conservadores. Nesse sentido, ele argumenta que a fantasia e o fantástico fazem parte do modus operandi das grandes narrativas religiosas ou dos produtos do entretenimento, mas não ressoa nas estratégias políticas progressistas daquele país.

A partir de Duncombe e sua ideia de Dreampolitik (uma clara referência à Realpolitik, o paradigma realista da política que se funda no pragmatismo), é possível identificar a falta de habilidade de setores progressistas em sonhar. Ele afirma: "Se os progressistas querem ser uma força política novamente, precisamos redescobrir como sonhar" (DUNCOMBE, 2019, p. 160). E a temática do sonho não aparece impunemente nessa reflexão, pois é o emblemático discurso de Martin Luther King que se traduz na referência de um projeto que, segundo o autor, precisa ser mais profundamente discutido.

O argumento de Duncombe é simples: é muito difícil sonhar com coisas que você não conhece e mesmo os desejos mais profundos de transformação carecem de um esforço imaginativo capaz de entregar algo concreto. O problema é que as políticas progressistas, de um modo geral, se detêm na crítica e análise do mundo como ele é e não assumem propostas sobre como esse mesmo mundo poderia ser. A Dreampolitik funda-se na ideia de como coisas podem ser quando tudo for diferente. A minha proposta, por sua vez, é compreender o esforço imaginativo que esses livros estabelecem e como delimitam esse poder ser, dando-lhe ao mesmo tempo forma, para que seja conhecida, e sentido para que promova ação. Em outras palavras, entendo que é possível encontrar entre os títulos apresentados uma imaginação política antagonista, capaz de não só elaborar o atual contexto político a partir de uma 
perspectiva crítica e oposicionista, como também imaginar possibilidades de resistência, formulando uma Dreampolitik.

Situar a imaginação antagonista a partir da produção editorial de 2019 no Brasil também requer uma reflexão sobre como a indústria criativa se relaciona com uma determinada contingência. Na história recente do país, o período da ditadura militar ilustra bem a capacidade do mercado editorial em se constituir como um campo produtor de reflexões de contestação. A partir da década de 1970, explica Maués (2014), "ganha corpo um movimento editorial que terá características de oposição ao governo ditatorial, e que tem início juntamente com o processo de distensão política que a cúpula militar no poder se viu na contingência de implementar" (p. 91). A produção desse período, "literatura política", foi basicamente escrita por atores políticos ligados a alguma forma de contestação do regime. Analisando esse fenômeno político-editorial, o autor argumenta que tanto as empresas quanto os profissionais envolvidos traziam na marca de suas produções uma "clara intenção política de intervenção social, tornando-se sujeitos ativos no processo político brasileiro no período final da ditadura" (p. 93).

Há certamente uma série de questões sobre como a literatura política atuou no processo de questionamento e enfraquecimento do regime militar e de como, mesmo dotados de uma clara vontade política, esses livros tinham limitações inerentes a sua própria constituição e ao contexto de censura e controle de produção e circulação. De um modo geral, entende-se que os livros nessa época eram mais do que um produto editorial e comercial, eram "uma manifestação política pública, que se dirigia aos formadores de opinião, ou ao menos tinha essa pretensão" (idem).

Repercutindo sobre esse engajamento pós-1964, Ridenti (2007) fala, numa perspectiva mais ampla, sobre a consolidação de uma indústria cultural atenta a um segmento de mercado (tipicamente organizado em torno da classe média) desejoso de consumir produtos culturais de contestação à ditadura. Isso pôde ser observado no êxito da Revista Civilização Brasileira, ou no enorme sucesso das canções engajadas dos festivais de música popular. O historiador aponta para a evidência de que havia "mudanças na configuração da sociedade brasileira: a ditadura promoveria certa modernização autoritária que contribuiria para alterar as predisposições revolucionárias nos meios artísticos e intelectuais" (p. 189). Muito embora não seja objetivo desse trabalho estabelecer um paralelo entre o que aconteceu com a indústria cultural brasileira pós-64 e o atual momento do mercado editorial, acho importante ressaltar como as "predisposições revolucionárias" se fortalecem na medida em que uma conjuntura 
autoritária toma forma. A imaginação antagonista também se sustenta nessa perspectiva, assumindo a natureza articulatória que as posições de contestação ensejam numa dada situação política.

\section{DESOBEDECER E ADIAR O FIM DO MUNDO}

"Ideias para adiar o fim do mundo" reúne e adapta duas palestras promovidas pelo líder indígena Ailton Krenak em Portugal, em 2017. Um livro curto, com pouco menos de 60 páginas, e que se baseia numa crítica à modernidade, que desconectou o homem da natureza, realizando uma "abstração civilizatória". Para o autor, esse processo retirou do homem o prazer de viver e de dançar, transformando a humanidade numa "humanidade zumbi". Ele explica:

O tipo de humanidade zumbi que estamos sendo convocados a integrar não tolera tanto prazer, tanta fruição de vida. Então, pregam o fim do mundo como uma possibilidade de fazer a gente desistir dos nossos próprios sonhos. E a minha provocação sobre adiar o fim do mundo é exatamente sempre poder contar mais uma história. Se pudermos fazer isso, estaremos adiando o fim (p. 13).

Entendo que as palavras de Krenak reverberam aquilo que Walter Mignolo (2010) chamou de "pensamento crítico de fronteira", uma reposta epistêmica do subalterno ao projeto eurocêntrico de modernidade. Também revela uma "desobediência epistêmica" (QUIJANO, 2005) que se põe a desencadear novos conceitos que desafiam o ordenamento geopolítico que concebe alguns saberes como "não-existentes". Assim, as ideias para adiar o fim do mundo demonstram como as populações indígenas veem sistematicamente desobedecendo ao "clube da humanidade" (KRENAK, 2019, p.8) e existindo, apesar das históricas ameaças e violências impetradas pelo ocidente civilizado e esclarecido em seu projeto colonizador. Adiar o fim do mundo é, portanto, um projeto de desobediência que Krenak apresenta com uma certa ironia indulgente de quem acumula uma experiência ancestral no assunto. Ele fala:

Em 2018, quando estávamos na iminência de ser assaltados por uma situação nova no Brasil, me perguntaram: "Como os índios vão fazer diante disso tudo?". Eu falei: "Tem quinhentos anos que os índios estão resistindo, eu estou preocupado é com os brancos, como que vão fazer para escapar dessa" (p. 15).

Existe uma experiência histórica específica (um saber "não-existente") que se apresenta como chave de compreensão do mundo (a "situação nova") e motivação para uma mudança de ação. Adiar o fim do mundo é uma prática conhecida dos povos originários, um 
ato de resistência histórica que atravessou cinco séculos de violência colonial. Como ele afirma, os povos originários conseguiram chegar ao século XXI, mesmo "quando a maior parte das previsões apostava que as populações indígenas não sobreviveriam à ocupação do território, pelo menos não mantendo formas próprias de organização, capazes de gerir suas vidas" (p. 20-21).

\section{COMO SERÁ O AMANHÃ: CONTEXTOS E POSSIBILIDADES PARA A ESPERANÇA}

A obra da antropóloga Rosana Pinheiro Machado "Amanhã vai ser maior: o que aconteceu com o Brasil e possíveis rotas de fuga" é também uma coletânea que reúne tanto textos adaptados e previamente publicados quanto algumas produções inéditas. No caso da autora, seu "lugar de fala" explicitado na obra (kindle, s/p) incorpora o duplo de acadêmica e intelectual pública. Seu propósito, resumido no título do trabalho, é responder a duas perguntas: o que está acontecendo com o país e como sair dessa situação. Para ela, "Sem observar como as fissuras democráticas ocorreram no dia a dia dos cidadãos comuns e as criativas formas de resistência [...], nós não conseguimos contar a história completa de como chegamos até aqui, [nem] pensar quais as possíveis rotas de fuga que temos” (kindle, s/p).

É impossível não levar em consideração a dimensão tanto analítica quanto prescritiva proposta na ideia de contar uma "história completa" e, ao mesmo tempo, pensar as "possíveis rotas de fuga" que definem o trabalho da autora. Uma formulação que muito tem a dizer sobre o papel do intelectual no espaço público atual, marcado, como assinala Beatriz Sarlo (1997) pela associação ao discurso especialista que a academia sistematicamente assumiu como exercício da crítica. Se deseja ser realmente eficaz, esse intelectual especialista (trazido e explicado no argumento do lugar de fala de Rosana na introdução do livro, quando ela descreve seu trabalho de campo na periferia de Porto Alegre) deve, "medir seu distanciamento crítico na escala dos milímetros, a fim de evitar uma separação grande demais da comunidade a qual se dirige" (p. 166). Isso porque a "intervenção heroica" do intelectual à moda antiga não impressiona mais as sociedades, que sabem que as mudanças podem ser alcançadas "sem a autoridade do guia iluminado", modelo que o trabalho intelectual adotou desde sua fundação iluminista.

Essa posição intelectual/especialista milimetricamente distante permite, por exemplo, que Rosana Pinheiro Machado se dedique a elaborar fenômenos como o crescimento da direita, a fragilidade das lideranças de esquerda e suas relações com as classes sociais. Nesse 
processo, ela aponta que não faz sentido chamar o trabalhador pobre que votou em Bolsonaro de fascista e coxinha, pois "Agindo assim, apenas afastamos essas pessoas de nós e as jogamos ainda mais para a direita, que, por sua vez, as recebe de braços abertos, sem nenhum pré-requisito" (kindle, s/p). Ao longo do livro, a autora propõe uma releitura de parte do eleitor de Bolsonaro em contraste ao estereótipo fascista do "bolsominion apaixonado". Faz parte de seu argumento um encadeamento de acontecimentos históricos, formando o que chama de uma "lógica fascista", que começa com os movimentos Occupy pelo mundo, passam pelas jornadas de junho de 2013 no Brasil, a "consagração da direita” nas eleições de 2014, o golpe contra a presidenta Dilma em 2016 e culmina com a eleição de Jair Bolsonaro, em 2018. Para ela, a lógica fascista brasileira é difusa e difícil de ser identificada, "pois propaga um ódio mais pulverizado, direcionado a uma massa diversa. [...] o fascismo idiossincrático à brasileira não idolatra a si próprio, mas sim aqueles países que nos barram na imigração" (kindle, s/p).

\section{POLISSEMIA DA IMAGINAÇÃO ANTAGÔNICA: ENTRE PARAQUEDAS COLORIDOS E AFETOS DE FUTURO}

É importante ressaltar que existe um caráter polissêmico em toda articulação antagonista, isso porque se se diversificam as formas de subordinação, ampliam-se também os questionamentos a elas. Como explicam Laclau e Mouffe (2015), há numerosas novas lutas que expressam novas formas de resistência, o que permite pensar sobre "a multiplicidade de relações sociais a partir das quais podem se originar antagonismos e lutas”. Nesse sentido, é importante ressaltar que o tema do antagonismo existe na obra dos autores como composição de um quadro teórico que se dedica a pensar a hegemonia como um tipo de relação política (p. 222). Esse pensamento assume como premissa a contestação da primazia da classe no pensamento político pois leva em conta a pluralidade de formas discursivas de se construir o antagonismo. Assim, além do fim do mundo e seu possível adiamento como proposto por Ailton Krenak, o pensamento político antagônico também comporta um forte investimento sobre as ideias de futuro, que as elaborações sobre o amanhã de Rosana Pinheiro Machado ensejam.

Para Krenak, experimentar o fim do mundo é a interrupção “de um estado de prazer extasiante que a gente não quer perder" (p. 30). É também como cair no abismo de tantas experiências como o consumismo, a Guerra Fria, os conflitos recentes etc. Nessa leitura, a 
humanidade segue com medo do que virá com a (ou depois da) queda, mesmo já tendo caído tantas vezes antes. Sua solução é simples: construir paraquedas coloridos para assim "não eliminar a queda, mas inventar e fabricar milhares de paraquedas coloridos, divertidos, inclusive prazerosos" (p. 31). Seguindo sua elaboração, Krenak explica que tais paraquedas só poderiam ser projetados nas visões e retoma mais uma vez o lugar do sonho em sua imaginação política, como potência de adiar esse mundo prestes a acabar. Ele explica:

O sonho como experiência de pessoas iniciadas numa tradição para sonhar. Assim como quem vai para uma escola aprender uma prática[...]. Alguns xamãs ou mágicos habitam esses lugares ou têm passagem por eles. [...] não é um mundo paralelo, mas que tem uma potência diferente. Quando, por vezes, me falam em imaginar outro mundo possível, é no sentido de reordenamento das relações e dos espaços, de novos entendimentos sobre como podemos nos relacionar com aquilo que se admite ser a natureza, como se a gente não fosse natureza. (p. 32).

Refletindo sobre essa metáfora de inventivos paraquedas coloridos, Seligmann-Silva (2020) explica como Walter Benjamin propôs, a partir da ideia de sonho e transe xamânico uma mobilização para a revolução ${ }^{2}$. A obra benjaminiana citada defende a "organização do pessimismo" em oposição à "péssima poesia de primavera" em que o "socialista vê o futuro mais belo dos nossos filhos e netos no fato de que todos agem 'como se fossem anjos', todos possuem tanto "como se fossem ricos', e todos vivem 'como se fossem livres"” (p. 33), mesmo não havendo vestígio real, nessas imagens de otimismo, de anjos, riqueza e liberdade. O pessimismo organizado, nesse sentido, não é contemplativo, mas prático, dedicado a impedir que o pior aconteça, numa luta que é pela imagem. Assim, organizar o pessimismo significa "extrair a metáfora moral da esfera pública e descobrir no espaço da ação política o espaço completo da imagem" (p. 34). A cena de paraquedas coloridos pairando no céu ressoa exatamente essas imagens que vão se não "impedir o pior", pelo menos acionar, como o próprio Krenak sugere, as subjetividades, a imaginação e as resistências necessárias para adiar o fim do mundo.

Por outro lado, o amanhã que Rosana Pinheiro Machado prevê é significativamente formulado pela elaboração da esperança. A autora fala em tradução da esperança no pensamento nacional, com os pés "na terra firme e em tudo que já existe em forma de luta e de arte. [...] articulando os antigos movimentos e os novos coletivos, [e] criando novos

2 É importante ressaltar que a ideia de revolução em nada se alinha com a epistemologia de Krenak: "Evidentemente, a ideia de "revolução", como vimos, não é parte do arcabouço ameríndio e sim um fruto de nosso pensamento judaico-cristão (e a seu modo marxista no caso de Benjamin). Mas isso não implica que não possamos encontrar afinidades aqui, pois Benjamin era um pensador do "tempo do agora' (Jetztzeit)" (SELIGMANN-SILVA. 2020). 
espaços para reforçar o cordão de resistência democrática" (kindle, s/p). A esperança é assim politicamente tematizada como afeto de resistências e ação, para ela: "No Brasil de hoje, [...] lamentamos a vitória da extrema-direita, não enxergamos saídas e deixamos que essa angústia nos imobilize. Outra alternativa - à qual este livro convida - é transmutar a dor em luta, e fazer da esperança uma opção política" (kindle, s/p). A referência freireana que marca a presença pública da autora deve ser ressaltada. Trazendo uma das últimas obras do intelectual recifense, Pedagogia da Esperança (FREIRE, 1992), Machado defende que a esperança é algo que se aprende, mais do que uma postura de espera. Reverberando a obra de referência, Machado postula a esperança como afeto que impede o sujeito de:

[se] acomodar aos discursos pragmáticos da economia e se adaptar aos fatos, especialmente diante daqueles que diziam que sonho e utopia eram inúteis e inoportunos. [...] a esperança é uma necessidade vital. A existência humana e a luta por uma sociedade melhor não podem ocorrer sem esperança e sem sonho. [...] (Kindle, s/p)

É interessante notar como existe um deslizamento sutil entre as imagens prescritivas das rotas de fuga para as projeções afetivas do amanhã maior, como lugar de esperança. Enquanto as rotas de fuga contam com uma tematização sobre o medo, a angústia e a paralização, as reflexões sobre o amanhã enumeram a criatividade, o sonho e a esperança. No primeiro caso, destacam-se os capítulos "Ódio, substantivo masculino" e "Da esperança ao ódio", em que a autora associa dois fenômenos centrais no crescimento do bolsonarismo: o papel da crise econômica na "crise do macho" brasileiro e a virada conservadora operada entre as elites políticas do pais, respectivamente. No segundo caso, destacam-se capítulos como "esperança, substantivo feminino" e "A extrema-direita venceu, as vedetes também". Neles, Rosana destaca o crescimento do pensamento feminista entre mulheres cada vez mais jovens e em geografias periféricas (a maré feminista, o \#EleNão) e estabelece:

Quando o desespero bater sob o governo autoritário e misógino de Jair Bolsonaro, será importante olhar para a frente e lembrar que muita energia está vindo de baixo, $[\ldots]$ as adolescentes feministas vão crescer, e o mundo institucional terá que mudar para recebê-las.

Quero me deter sobre essas projeções afetivas do amanhã partindo do que Safatle (2016) discute como a dimensão política da esperança e de como esse afeto mobiliza a relação das pessoas com o tempo. O autor destaca: “ [a esperança] é um modo de síntese do tempo que [estabelece] [...] uma relação com o que os teóricos da história chamarão de 'horizonte de expectativa"” (p. 98). O tempo futuro é, assim, um vetor fundamental da esperança, um afeto 
feminino, como pontua a Rosana Pinheiro-Machado (2019), que opera numa ética combativa, cuja forma Freire (1992) explica:

[sem a esperança] pouco podemos fazer porque dificilmente lutamos e quando lutamos, enquanto desesperançados ou desesperados, a nossa luta é suicida, é um corpo a corpo puramente vingativo. O que há, porém, de castigo, de pena, de correção, de punição na luta que fazemos movidos pela esperança, pelo fundamento ético-histórico de seu acerto, faz parte da natureza pedagógica do processo político de que a luta é expressão (p. $11)$.

Entendo que existe uma afinidade ética entre o "fim do mundo" de Krenak e o “amanhã” de Machado, o que revela um aspecto importante da imaginação antagonista. Essa elaboração do tempo a respeito do Brasil indica uma cronotopia pautada pela criatividade e esperança. Categoria bakhtiniana para a análise estética do romance, o cronotopo de um texto não pode, conforme explica Irene Machado (1998), se separar da concepção de mundo e de homem na qual ele está inscrito. Nesse sentido, a autora ressalta como a medida do tempo tem um valor importante para o cronotopo, uma vez que não assume formas lineares (o hoje ligado ao que passou e ao que virá) mas postula o tempo como simultaneidade na coexistência e interação e na percepção do devir.

Nessa perspectiva, o cronotopo da imaginação antagonista não se interessa, portanto, em pensar sobre convenções a respeito do tempo e sim como os enunciados sobre ele revelam uma determinada forma de ver o mundo (ou, no caso de Krenak, o fim do mundo). Irene Machado (1998) explica ainda que nos estudos de Bakhtin sobre o tema, "A narrativa torna-se um campo fértil de investigação pois nela se constituem os discursos sobre o mundo a partir dos quais é possível pensar as relações dialógicas". (p.34). O tempo dessa imaginação antagonista é sem dúvida aquele do futuro, ela olha o devir com expectativas criativas (como paraquedas coloridos) e de esperança (o combustível da resistência).

\section{ENTRE O FIM DO MUNDO E O AMANHÃ, ALGUMAS CONSIDERAÇÕES PARCIAIS}

Uma das motivações iniciais para a produção desse trabalho foi a observação de duas iniciativas que buscavam contestar uma ordem política vigente a partir da distribuição gratuita de livros. As campanhas dos livreiros de Whasihington contra Trump em 2017 e do digital influencer Felipe Neto contra o veto de Crivela a um título de HQ na Bienal de 2019 foram ações que se deram em contextos completamente distintos e sem qualquer conexão entre si. 
No entanto, ambas guardam em comum não só a estratégia de disponibilização dos títulos aos leitores como também a assunção de que a leitura pode ser uma forma eficiente de conter o avanço de forças políticas autoritárias ou censórias. Ler e agir, como uma das campanhas sugeria, me pareceu uma boa pista a seguir na tentativa de entender as formas como uma imaginação antagonista, articuladora de várias perspectivas diferentes, mas com uma posição crítica em comum sobre uma determinada ordem política vigente, pode se apresentar e ser consumida no mercado editorial.

Assumi, nesse trabalho, que uma parte relevante da imaginação antagonista no mercado editorial brasileiro atual não se dá apenas pelo fato de que os títulos compartilham um posicionamento contrário à atual configuração política do país. O investimento na compreensão do quadro atual, seja através de um posicionamento de fronteira como é o caso da proposta de Krenak, seja através de um discurso intelectual especialista, como foi o caso de Rosana Pinheiro Machado, é também uma demanda de mercado. É o que provam pesquisas sobre o crescimento da procura por títulos políticos no país. Segundo levantamento feito pela Nielsen Bookscan e publicado pela Revista Istoé (2020), a média mensal de venda de livros com temática política (não levando em consideração o espectro político ao qual se referia) cresceu 300\% entre 2013 e 2019. Para um mercado comumente associado ao declínio e crise, a demanda por livros tão específicos foi interpretada pelos condutores do estudo como produto da recente conjuntura política não só do país, mas do mundo.

Além de uma pesquisa qualitativa para pensar sobre as formas e efeitos de sentido dessa imaginação antagonista entre os títulos que se propõem a entender o (e a resistir ao) atual contexto político, seria necessário também uma abordagem longitudinal para acompanhar esses títulos. Nesse sentido, muitas perguntas poderiam ser feitas. Trata-se de uma tendência de mercado duradoura ou um fenômeno localizado? É possível enquadrar esse tipo de produção num determinado nicho? É possível estabelecer, como Borges (2015) fez ao relatar o crescimento da direita no Brasil, uma relação entre o aumento da produção editorial animada por essa imaginação e o desenvolvimento de formas políticas de resistência?

São, de fato, perguntas pertinentes para a compreensão do mercado editorial e sua relação com o contexto político, mas defendo que é importante assumir como ponto de partida a imaginação política antagonista que esses títulos ensejam ${ }^{3}$. Nos dois casos analisados, existe

\footnotetext{
${ }^{3}$ Um teste interessante para avaliar a performance dessa imaginação no mercado editorial poderá ser feito a partir do agendamento que a pandemia da Covid-19 começa a empreender nas prateleiras das livrarias. Já se percebe uma crescente produção desses títulos no mercado, propondo hermenêuticas políticas para o vírus e seus efeitos. O próprio Krenak lançou "O amanhã não está à venda", onde debate a urgência imposta pelo vírus em
} 
um investimento significativo na formação de uma ideia de futuro que tanto o fim do mundo quanto o amanhã evocam através do sonho e da esperança, de um saber fronteiriço ou intelectual. Um tempo marcado por incerteza, mas potente de possibilidades de resistência, seja por conta dos paraquedas coloridos que adiam o fim do mundo, ou pela esperança do amanhã maior.

Nessas duas construções, a referência ao sonho é um aspecto importante sobre a imaginação protagonista e assume a afinidade com a Dreampolitik, que é imaginar como o mundo pode ser diferente. Entendo que essa imaginação encontrará possibilidades de se constituir a partir de outras formas de enunciação, como mostra o arquivo mais amplo, apresentado no início do trabalho. A figura religiosa de um pastor evangélico progressista, a abordagem interseccional proposta por uma intelectual negra, o relato biográfico de uma política feminista ou as memórias de político exilado são parte disso. Por isso, é possível que à medida que se avança no acirramento da situação política que instaura as posições antagonistas, mais títulos surjam, uma vez que o espectro desse antagonismo vai se tornando cada vez mais amplo, articulando cada vez mais posições.

\section{REFERÊNCIAS}

BORGES, Rodolfo. A direita brasileira que saiu do armário e não para de vender livros. 01 Ago 2015. Disponível em: https://brasil.elpais.com/brasil/2015/07/22/politica/1437521284_073825.html Acesso em 01 Maio 2020.

DARDOT, Pierre; LAVAL, Christian. A nova razão do mundo: ensaio sobre a sociedade neoliberal. São Paulo: Boitempo, 2015.

DUNCOMBE, Stephen. Dream or Nightmare: Reimagining Politics in an Age of Fantasy. New York and London: OR BOOKS, 2019.

ESTADO DE SÃO PAULO. 'Mandamos um recado claro para a censura', diz Felipe Neto após distribuir livros LGBT na Bienal. São Paulo: 08 Set 2019. Disponível em:

https://emais.estadao.com.br/noticias/gente,mandamos-um-recado-claro-para-a-censura-diz-felipeneto-apos-distribuir-livros-lgbt-na-bienal,70003002119 Acesso em 01 maio 2020.

FERREIRA, Afonso. HQ dos Vingadores proibida na Bienal do livro chega a custar R \$ 250 na Web. São Paulo: 10 Set 2019. Disponível em:

https://entretenimento.uol.com.br/noticias/redacao/2019/09/10/hq-vingadores-bienal-do-livro.htm Acesso em 01 Maio 2020.

FREIRE, Paulo. Pedagogia da esperança: um reencontro com a pedagogia do oprimido. Rio de Janeiro: Paz e Terra, 1992.

repensar os modos de vida eurocentrados, uma abordagem que dialoga diretamente com o escopo de "Ideiais para adiar o fim do mundo". 
HEINEN, Eduarth; RIBEIRO, Marcio; ORTELLADO, Pablo. Esquerda e direita estão obcecadas em detratar o adversário. 17 Set 2019. Disponível em:

https://www1.folha.uol.com.br/ilustrada/2019/09/esquerda-e-direita-estao-obcecadas-em-detratar-oadversario.shtml. Acesso em: 30 Abr 2020.

KRENAK, Ailton. Ideias para adiar o fim do mundo. São Paulo: Companhia das Letras, 2019.

LACLAU, Ernesto; MOUFFE, Chantal. Hegemonia e Estratégia Socialista: por uma política democrática radical. São Paulo: Editora Entremeios, 2015.

MACHADO, Irene. Narrativa e combinatória dos gêneros prosaicos: a textualização dialógica. Itinerários, Araraquara, n. 12, p. 33-46, 1998.

MACHADO, Rosana Pinheiro. Amanhã vai ser maior: o que aconteceu com o Brasil e possíveis rotas de fuga para a crise atual. São Paulo: Planeta do Brasil, 2019 (kindle).

MAUÉS, Flamarion. Livros, editoras e oposição à ditadura. Estudos Avançados, São Paulo, v. 28, n. 80, p. 91-104, 2014.

NUNES, Rodrigo. Pandemia e Polarização. Abril de 2020. Disponível em:

https://www.revistaserrote.com.br/2020/04/pandemia-e-polarizacao-por-rodrigo-nunes/. Acesso em 01 Maio 2020.

REVISTA ISTOÉ. Mercado Editorial Melhor. São Paulo: 4 Jun 2020. Disponível em: < https://istoe.com.br/mercado-editorial-melhor/>. Acesso em 10 Jun 2020.

RIDENTI, Marcelo. Intelectuais e artistas brasileiros nos anos 1960/70: "entre a pena e o fuzil". ArtCultura, Uberlândia, v. 9, n. 12, p. 185-195, 2007.

SAFATLE, Vladimir. O circuito dos afetos: corpos políticos, desamparo e o fim do indivíduo. Belo Horizonte: Autêntica, 2016.

SARLO, Beatriz. Cenas da vida pós-moderna: Intelectuais, arte e vídeo-cultura na Argentia. Rio de Janeiro: Editora UFRJ, 1997.

SELIHMANN-SILVA, Márcio. Construir paraquedas coloridos? Corona e os sonhos para além do apocalipse e da redenção. 01 Maio 2020. Disponível em:

https://artebrasileiros.com.br/opiniao/construir-paraquedas-coloridos-corona-e-os-sonhos-para-alemdo-apocalipse-e-da-redencao/ Acesso em 20 Maio 2020.

SILVA, Leandro Nóbrega. O mercado editorial e a nova direita. Teoria e Cultira, Juiz de Fora, v. 13, n. 2, p. 73-84, 2018.

STARLING, Heloisa. Se o impensável acontecer, mantenha a calma. 2020. Disponível em: https://www.revistaserrote.com.br/2020/05/se-o-impensavel-acontecer-mantenha-a-calma-por-heloisam-starling/ Acesso em: 30 Abril 2020.

STARLING, Heloisa. Um antivírus contra a tirania: Hannah Arendt e "Origens do Totalitarismo". 21 de Julho de 2017. Disponível em: http://www.blogdacompanhia.com.br/conteudos/visualizar/Umantivirus-contra-a-tirania-Hannah-Arendt-e-Origens-do-totalitarismo Acesso em 30 de Abril 2020. 


\section{Carolina Cavalcanti Falcão}

Jornalista, Mestre e Doutora em Comunicação pelo Programa de Pós-Graduação em Comunicação da UFPE. Atualmente atua como pesquisadora de pós-doutorado no Programa de Pós-Graduação em Direitos Humanos (PPGDH) da mesma instituição, onde desenvolve pesquisas sobre ativismos religiosos, democracia e antagonismo social e político.

\section{(ब) $(\Theta 0$}

Esta obra está licenciada com uma Licença

Creative Commons Atribuição-NãoComercial-CompartilhaIgual 4.0 Internacional 